\title{
Effect of the light on adenine nucleotide content of georeacting maize roots
}

\author{
Paul Steck and Paul-Emile Pilet \\ Institute of Plant Biology and Physiology of the University, \\ 1005 Lausanne, 6 Pl. Riponne, Switzerland
}

(Received October 17, 1978)

\begin{abstract}
Apical segments from maize roots of LG 11 and Orla 264 varieties georeacted, at least for the first few hours, only in light, while those of the Anjou 210 variety were georeactive both in light and darkness. The energy charge in the apical end of the two light geo-sensitive (LG and Orla) maize roots significantly increased in the light. In contrast, in Anjou root tips, the energy charge was already high in the dark and did not change significantly after light exposure. The time course of light-induced changes in adenine nucleotide contents in root tips was compared with varietal differences in georeactivity in light and darkness. The present data corroborate the hypothesis that a high energy state in the root tip is a prerequisite for the expression of the root reaction to gravity.

Key words: Adenine nucleotides - Energy charge - Georeaction - Light effect Root - Zea mays.
\end{abstract}

Light may change the level of endogenous adenine nucleotides in etiolated plant tissues but its action is far from clear. The decrease in ATP content of mung bean root tips, reported by Yunghans and Jaffe (36), was not confirmed by Bürcky and Kauss (3) who rather found a slight increase in the ATP level after light presentation. The rise of ATP observed by White and Pike (33) disappeared after a few minutes. Usually, the adenylate system is regulated by endogenous "homoeostasis" and light does not alter ATP levels in etiolated plant organs $(4,28)$.

However, using a microgradient technique (11), a significant difference has been found between the ATP contents of maize roots exposed to light compared with dark controls (17). The sensitivity of the root to light is essentially in the root cap where growth-inhibiting substances are formed or released in response to light (10, $14-22,32,34)$. On the other hand, the role of the cap cells in the geogreactivity of roots seems to be similar to their role in the growth response to light $(17,20,35)$. Growth inhibitors produced in the cap on exposure to light (27) can be used by the root to produce curvature in response to gravitational stimulation in darkness, i.e., under conditions in which dark-exposed roots do not normally respond to gravity $(21,35)$. Using two maize varieties-Kelvedon33, which requires light for georeaction, and Anjou 210, which does not-and exchanging their root caps has shown that the curvature of the root stumps is only related to the biological nature of the cap $(16,17)$. Using Orla 264 maize roots, which only georeact in light $(20)$, at 
least for the first few hours of geopresentation, the ATP level in the georeacting part of the root was found to be higher in light than in darkness; in Anjou maize, no significant differences were found in the longitudinal distribution of ATP in lightexposed roots compared with those kept in the dark (23).

The aim of the present work was to investigate the time course of the lightinduced changes in endogenous adenine nucleotide contents in roots of several maize varieties and to compare them with varietal differences in georeactivity in light and darkness.

\section{Materials and methods}

Three varieties of Zea mays L. were used: cv. LG 11 (Association Suisse Sélectionneurs, Lausanne), cv. Orla 264 (idem), and cv. Anjou 210 (Hodée, Beauforten-Vallée, France). The conditions for preparing the maize seedlings have been previously described (19). After $24 \mathrm{hr}$ of soaking in tap water, selected cayopses were grown in the dark between sheets of moist paper towels at 19 or $21^{\circ} \mathrm{C}$ according to the variety. These temperatures were maintained throughout the experiments. When the primary roots-which elongated vertically-reached $15 \pm 3 \mathrm{~mm}$ in length, they were selected under green light $(530 \pm 20 \mathrm{~nm})$ and rectilinear apical segments $(10 \pm 0.2 \mathrm{~mm})$ were mounted in plastic frames with their basal ends in contact with moist filter paper. The frames were then placed in closed boxes (relative humidity $90 \pm 5 \%$ ). Curvatures of the root segments were recorded by taking shadow photographs.

For the nucleotide analyses, $3.5 \mathrm{~mm}$ portions of $15 \pm 3 \mathrm{~mm}$ primary roots from identically grown seedlings were cut off and rapidly frozen in liquid nitrogen. Five lyophilized portions per sample were ground and immersed for $10 \mathrm{~min}$ in $7 \mathrm{ml}$ boiling Tris buffer containing $\mathrm{MgSO}_{4}, \mathrm{~K}_{2} \mathrm{SO}_{4}$ and $\operatorname{EDTA}(29,31) \mathrm{pH}$ 7.4. The extracts were then immediately frozen and kept at $-25^{\circ} \mathrm{C}$ until the nucleotides were assayed. ATP was tested as already described (29) by automatically injecting (Fisons Diluter Type LFA 20) $100 \mu$ of firefly extract (FLE-250, Sigma Chemical Co.) and $700 \mu \mathrm{l}$ of extraction buffer, into $200 \mu \mathrm{l}$ of extract with or without internal ATP standard. The light emitted by the reaction was measured for $10 \mathrm{sec}$ using a Bioluminescence Photometer XP 2000 (Skan, Basel) coupled with a digital integrator. ADP and AMP were estimated after they had been converted to ATP by incubating the extracts with pyruvate kinase (in the presence of phosphoenopyruvate) and adenylate kinase (24). The energy charge, (ATP +1/2ADP)/(ATP + ADP + AMP), was then calculated. As defined by Atkinson (1), this parameter is linearly related to the amount of metabolically available energy that is momentarily stored in the adenylate system; it varies between 0 when only AMP is present and 1 when all adenylate is in the form of ATP. Standard errors of the mean were calculated for all results and significant differences were assessed by the $t$ test.

For light assays, the closed boxes containing the biological material were exposed to white fluorescent light (Osram L: $13 \mathrm{w} / 25$-kyX, Secfroid, Lausanne; 0.90 $\left.\pm 0.06 \mathrm{~J} \mathrm{~m}^{-2} \mathrm{sec}^{-1}\right)$ and the temperature was maintained at the same value as in the dark experiments $\left(19\right.$ or $\left.21^{\circ} \mathrm{C}\right)$. 


\section{Results}

\section{Georeaction in the dark and in light}

In the first set of assays, the geotropic curvature of apical root segments prepared from primary maize roots was analyzed from 0 (starting measurement with segments just placed in the horizontal position) to 12 hours (Fig. 1). Curvature was recorded every 2 or $4 \mathrm{hr}$ for the segments kept in darkness or light (A: cv LG 11; B: cv Orla 264; C: cv Anjou 210). In the light, all these roots showed a strong georeaction, which was more pronounced for LG and less for Anjou. On the other hand, roots from Anjou reacted in both darkness and light, while those from LG and Orla were, at least for the first few hours, strongly geotropic only in light.

From these data, the velocity of the geotropic reaction was calculated for the first two hours and the results are given in Table 1. The georeactive rate was smaller for the roots maintained in darkness for all the varieties tested. In both light and darkness, this velocity was lowest for the Orla roots. However, with regard to influence of light, roots of LG and Orla have similar georeactivity in comparison with those of Anjou.

\section{Longitudinal distribution of endogenous adenine nucleotides in maize roots kept in the dark}

Roots and root segments were prepared in the dark from the three varieties of maize. Table 2 shows the absolute level of ATP, ADP and AMP for several parts of the root. First, note that the total amounts of adenine nucleotides in roots of
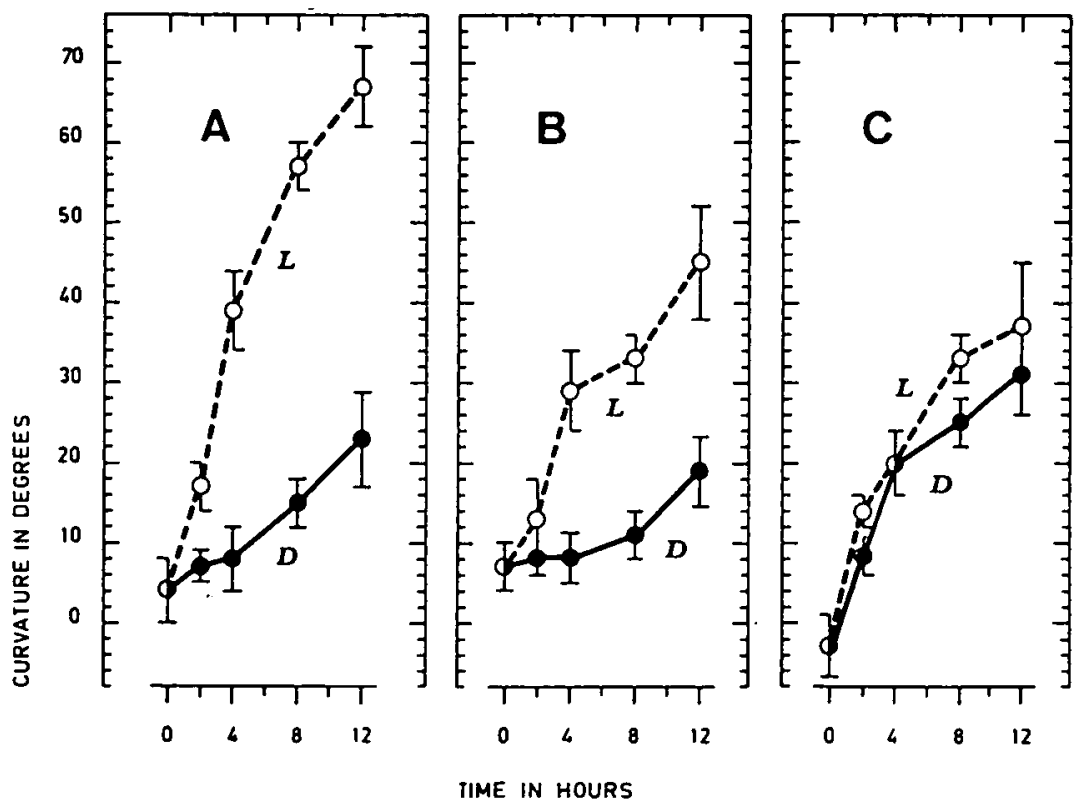

Fig. 1. Curvalure (in degress \pm standard deviation) in relation to lime (in hours) of apical root segments prepared from three maize varieties, horizontally placed at $0 \mathrm{hr}$ in darkness (D) or in light (L). A: cv LG 11, B: cv Oria 264, C: cv Anjou 210. For each value, $42 \pm 6$ roots were used and the assays were repeated 4 (A) or 3 times $(B, C)$. 
Table 1 Velocily (in degrees per hr) of the first 2-hr georeaction of apical root segments of three maize varieties, horizontally placed at $\mathrm{O} \mathrm{hr}$ in the dark and light

\begin{tabular}{lcc}
\hline Maize variety & Dark reaction & Light reaction \\
\hline cv LG 11 & 1.59 & 6.31 \\
cv Orla 264 & 0.47 & 3.05 \\
cv Anjou 210 & 6.03 & 8.24
\end{tabular}

Data were calculated from the results given in Fig. 1 in which the standard deviation for each mean value is given.

LG 11 and Orla 264 varieties were much smaller than those for the Anjou 210 variety. Next, the longitudinal distribution was nearly the same for LG and Orla, with a higher concentration of nucleotides in the first apical part, while in Anjou, the level of adenine nucleotides was greater in the second zone. In this second part, the distribution of the three nucleotides was similar for the three varieties, while in the apical part, the differences in the size of the nucleotide pool were to a great extent due to the ATP content. Consequently, as will be seen later, the energy charge was much smaller in the first $3.5 \mathrm{~mm}$ part of LG or Orla roots than in the corresponding part of the Anjou root.

Effect of light on adenine nucleotide distribution and energy charge in different zones of the maize root

As previously discussed, the roots of LG and Orla exhibit a light-requiring geotropic response whereas those of Anjou are georeactive both in light and darkness. Therefore the effect of light on the levels of endogenous adenine nucleotides was measured in three parts of the root from the three varieties.

The data presented in Table 3 indicate that the largest change in the adenine nucleotide distribution due to light treatment occurred in the first apical zone (0-

Table 2 Longitudinal distribution of adenine nucleotides in maize root

\begin{tabular}{cccccc}
\hline Variety & Root zone $^{a}$ & ATP & ADP & AMP & $\Sigma^{b}$ \\
\hline cv LG 11 & $0.0-3.5$ & $1.44 \pm 0.13$ & $1.73 \pm 0.09$ & $2.26 \pm 0.12$ & $5.43 \pm 0.19$ \\
& $3.5-7.0$ & $1.59 \pm 0.07$ & $1.33 \pm 0.09$ & $1.81 \pm 0.19$ & $4.73 \pm 0.14$ \\
& $7.0-10.5$ & $0.97 \pm 0.06$ & $0.97 \pm 0.04$ & $0.98 \pm 0.08$ & $2.92 \pm 0.11$ \\
cv Orla 264 & $0.0-3.5$ & $1.35 \pm 0.07$ & $1.81 \pm 0.09$ & $2.04 \pm 0.01$ & $5.20 \pm 0.17$ \\
& $3.5-7.0$ & $2.04 \pm 0.14$ & $1.50 \pm 0.11$ & $1.37 \pm 0.16$ & $4.91 \pm 0.18$ \\
& $7.0-10.5$ & $1.33 \pm 0.06$ & $1.08 \pm 0.15$ & $0.99 \pm 0.12$ & $3.40 \pm 0.14$ \\
cv Anjou 210 & $0.0-3.5$ & $3.70 \pm 0.11$ & $2.70 \pm 0.16$ & $1.78 \pm 0.14$ & $8.18 \pm 0.16$ \\
& $3.5-7.0$ & $3.64 \pm 0.16$ & $2.97 \pm 0.19$ & $3.68 \pm 0.24$ & $10.29 \pm 0.31$ \\
& $7.0-10.5$ & $1.73 \pm 0.10$ & $1.67 \pm 0.08$ & $2.42 \pm 0.02$ & $5.82 \pm 0.22$ \\
\hline
\end{tabular}

a Millimeters from the tip of the root.

- $\Sigma=$ ATP +ADP +AMP. All results are mean values (in nanomoles per segment) given at $95 \%$ confidence limits. 
Table 3 Effect of light on adenine nucleotide distribution (in $\%$ of $\Sigma=\mathrm{ATP}+\mathrm{ADP}+\mathrm{AMP}$ ) and the energy charge (EC) in maize root

\begin{tabular}{|c|c|c|c|c|c|c|c|c|c|}
\hline \multirow{2}{*}{ Variety } & \multirow{2}{*}{ Root zone ${ }^{a}$} & \multicolumn{2}{|c|}{ ATP } & \multicolumn{2}{|c|}{$\overline{\mathrm{ADP}}$} & \multicolumn{2}{|c|}{ AMP } & \multicolumn{2}{|c|}{$\mathrm{EC}$} \\
\hline & & $\mathrm{D}$ & $\mathrm{L}^{b}$ & $\mathrm{D}$ & $\mathrm{L}$ & $\mathrm{D}$ & $\mathrm{L}$ & $\mathrm{D}$ & $L$ \\
\hline \multirow[t]{3}{*}{ cv L.G 11} & $0.0-3.5$ & 26.5 & $47.4 * *$ & 31.9 & 31.3 & 41.6 & $21.3 * *$ & 0.42 & $0.63 * *$ \\
\hline & $3.5-7.0$ & 33.6 & $29.2 *$ & 28.1 & 30.4 & 38.3 & 40.4 & 0.48 & 0.44 \\
\hline & $7.0-10.5$ & 33.2 & 31.9 & 33.2 & 31.4 & 33.6 & 36.7 & 0.50 & 0.48 \\
\hline \multirow[t]{3}{*}{ cv Orla 264} & $0.0-3.5$ & 26.0 & $52.4^{* *}$ & 34.8 & 33.9 & 39.2 & $13.7^{* * *}$ & 0.43 & $0.69 * *$ \\
\hline & $3.5-7.0$ & 41.5 & $35.2^{*}$ & 30.5 & 30.6 & 27.9 & $34.2 *$ & 0.57 & $0.50 *$ \\
\hline & $7.0-10.5$ & 39.1 & 41.6 & 31.8 & 30.9 & 29.1 & 27.5 & 0.55 & 0.57 \\
\hline \multirow[t]{3}{*}{ cv Anjou 210} & $0.0-3.5$ & 45.2 & 43.9 & 33.0 & 32.6 & 21.8 & 23.5 & 0.62 & 0.60 \\
\hline & $3.5-7.0$ & 35.4 & 35.4 & 28.9 & 29.3 & 35.8 & 35.3 & 0.50 & 0.50 \\
\hline & $7.0-10.5$ & 29.7 & 30.8 & 28.7 & 28.4 & 41.6 & 40.8 & 0.44 & 0.45 \\
\hline
\end{tabular}

aillimeters from the tip of the root.

b L: $60 \pm 5 \mathrm{~min}$ of light exposure. Statistically significant differences from the dark control (D): $* \mathrm{p}<0.05, * * \mathrm{p}<0.01$.

$3.5 \mathrm{~mm}$ ) from LG and Orla maize roots. The ATP content rose significantly while the AMP level decreased. Consequently, the energy charge was enhanced by light. In the second part (3.5-7 mm) of these roots, changes were smaller and in the opposite direction; the ATP level decreased slightly while the AMP level rose so that the energy charge was slightly reduced.

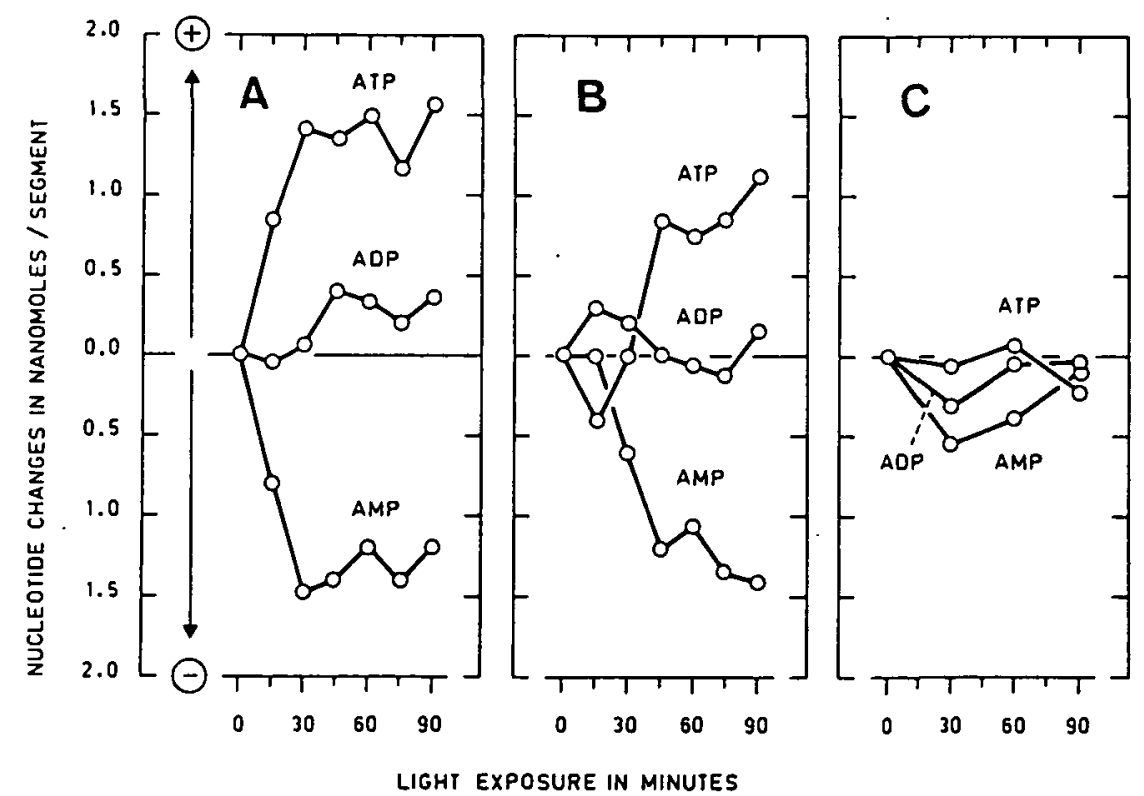

Fig. 2. Time course of change in endogenous adenine nucleotides levels in root tips $(3.5 \pm 0.1 \mathrm{~mm})$ of three maize varieties under white light (onset at zero time). Each point represents the mean value of two samples of five apical root portions from LG (A), Orla (B) or Anjou (C) maize. 


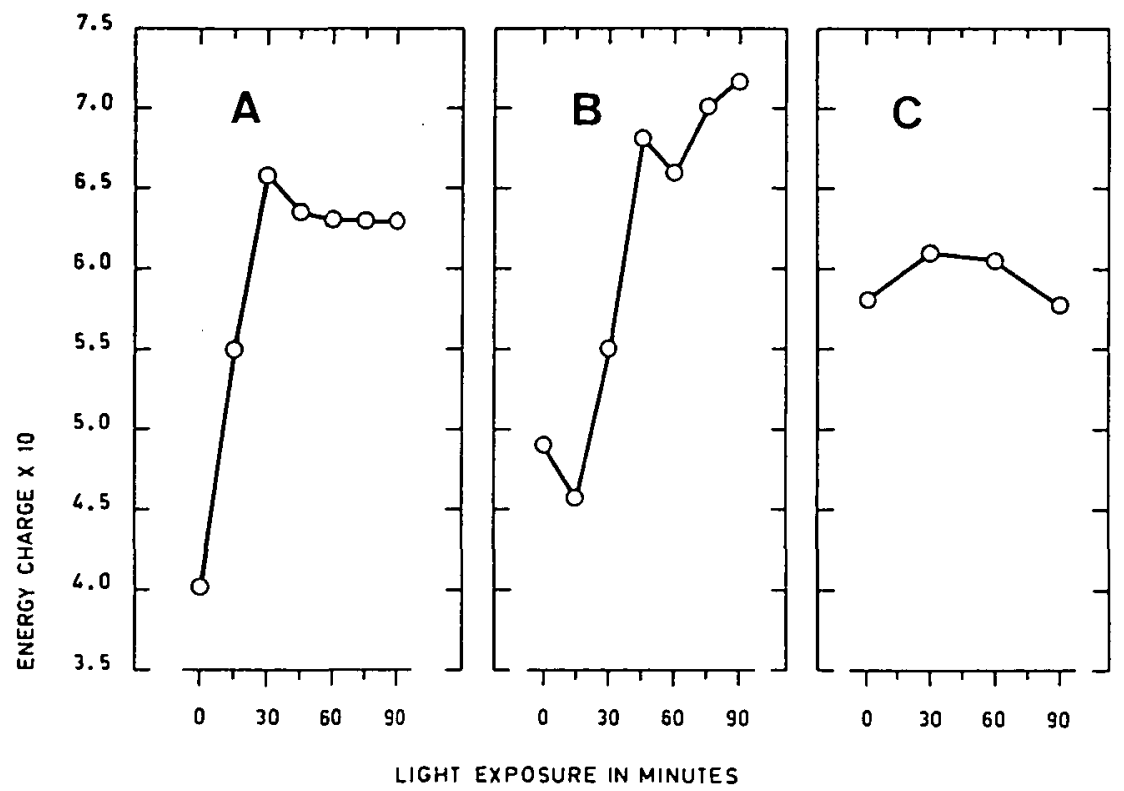

Fig. 3. Effect of white light (onsel at zero time) on the energy charge in the root tip for different varieties of maize. This parameter (see text) was calculated from the results given in Fig. 2.

In contrast, little if any change in the adenine nucleotide distribution was observed along the root from Anjou after light treatment. The energy charge in the first apical segment (0-3.5 mm) was already higher in the dark for roots of this variety than for the other two. It remained at a high value, of the same order as the values reached under light in the equivalent zone of the roots prepared from the two light-geosensitive maize varieties.

\section{Kinetics of light-induced changes in adenine nucleotide content and energy charge of the root tip}

As the main differences of endogenous adenine nucleotides levels due to light treatment were observed in the first apical part $(0-3.5 \mathrm{~mm})$ of the root, it was of interest to study the kinetics of these variations in this region. The time courses of changes in the levels of ATP, ADP and AMP for the apical part of light-exposed maize roots are given in Fig. 2. For LG, immediate modifications of ATP and AMP levels were obtained, while the ADP content remained approximately constant during the 90 min of light exposure. A similar effect but delayed by about $30 \mathrm{~min}$ was obtained for Orla. In contrast, no significant variation of endogenous adenine nucleotides was detected for the root tip from Anjou.

For the same root segments, the energy charge was calculated and the data are reported in Fig. 3. From these results, we can conclude that as the light treatment induced an increase in the ATP content and a decrease in AMP, the energy charge markedly increased for roots of both LG and Orla. In contrast, the energy charge remained constant for Anjou roots. Again the effect of light was delayed for Orla maize in comparison with LG. 


\section{Discussion}

As previously reported for several plant species $(6,9,13,20)$ and in particular for some varieties of maize $(16,17,20,26,35)$, the exposure of both LG 11 and Orla 264 root segments to light enhanced their ability to respond to gravity (see Fig. $1 \mathrm{AB}$ ). However, the necessity for light as a prerequisite for the normal geotropic response does not exist for Anjou maize root (see Fig. 1C) as already observed for cress (5), maize $(16,20)$, and spruce (7) roots; the georeaction of Anjou roots is the same in light and darkness, at least for the first few hours of graviperception.

In the dark, the maize roots which do not respond to gravity (LG and Orla) show a low ATP level and a low energy charge (see Tables 2 and 3). In contrast, for all the georeactive roots tested (LG and Orla in light, Anjou in light and darkness), both the ATP content and the energy charge were significantly higher. It can be concluded from these results that the geosensitivity of maize roots might in some way be related to a high energy state in the apical part of the root. The necessity for light to enhance the ability of LG and Orla roots to become normally georeactive must be related to the significant increase of the energy charge in these roots during light exposure. The lack of the light prerequisite for the normal georeaction of Anjou roots may be due to the already high energy charge in the dark for this variety.

Changes in ATP content could be a direct consequence of the light actionpresumably via the phytochrome system (33) which has been found in root tips $(25,30)$-on the in vivo reactions generating or consuming ATP. The resultant higher energy charge might be a prerequisite for the action of growth inhibitors from the root cap. Changes in the ATP level in the root tip may also be a rather nonspecific consequence of alterations in overall cellular activity induced by the growth inhibitors released from the cap by the light exposure.

According to Wilkins and Wain (35), LG 11 maize roots pretreated with white light before geotropic stimulation bent more rapidly than those maintained in darkness prior to the stimulation. These results corroborate the first point of view. It seems clear that the slower georeaction of Orla maize roots in light in comparison with LG and Anjou (see Table 1) is correlated with the delayed enhancement in the ATP level and the energy charge observed for the Orla roots brought into light (see Fig. 2B and 3B). On the contrary, the roots for which the energy charge is already high in the dark (Anjou) show the highest rate of georeaction. These results also agree with the hypothesis that a high energy state in the root tip is a prerequisite for the expression of the reaction of roots to gravity.

Now it is obvious that the first few apical millimeters of a root tip is a very complex system including cap, meristems, quiescent center, and the elongating and georeacting zone (19). Consequently, further studies are needed to determine more precisely in which part of the root tip occur the increases of ATP content and energy charge when the root becomes geosensitive under light. Our previous results (23) support the contention that the main increase of ATP content takes place in the growing and georeacting zone. The growth-inhibiting substances produced (or released) in the root cap and moving preferentially in the basipetal direction $(18,27)$ must control the cell growth in this zone. Although a clear correlation between growth and ATP level is difficult to demonstrate $(28,29)$, there is a general consensus of opinion that the growth has an energy requirement and therefore must 
depend on the energy state of the tissue. The results reported here lead to the obvious conclusion that georeaction-which is directly connected to the growth of this particular zone $(2,8,12)$-is also closely dependent on adenylate metabolism.

\section{References}

(1) Atkinson, D. E. and G. M. Walton: Adenosine triphosphate conservation in metabolic regulation. J. Biol. Chem. 242: 3239-3241 (1967).

(2) Béjaoui, M. and P. E. Pilet: Oxygen uptake of growing and geostimulated roots. Plant Sci. Let. 8: 223-226 (1977).

(3) Bürcky, K. and H. Kauss: Veränderung im Gehalt an ATP und ADP in Wurzelspitzen der Mungobohne nach Hellrotbelichtung. Z. Pfanzenphysiol. 73: 184-186 (1974).

(4) Friederich, K. E. and H. Mohr: Adenosine 5'-triphosphate content and energy charge during photomorphogenesis of the mustard seedling Sinapis alba L. Photochem. Photobiol. 22: 49-53 (1975).

(5) Iversen, T.H.: The roles of statoliths, auxin transport, and auxin metabolism in root geotropsim. K. Nor. Vidensk. Selsk. Musk. Misc. 15: 1-216 (1974).

(6) Iversen, T. H., C. Baggerud and K. Siegel: The effect of abscisic acid (ABA) and 3,5-diiodo4-hydroxybenzoic acid (DIHB) on elongation and geotropic development of lettuce and cress roots. Z. Pflanzenphysiol. 84: 339-348 (1977).

( 7 ) Iversen, T. H. and K. Siegel: The geotropic curvature in roots of Norway spruce (Picea abies L.) containing anthocyanins. Physiol. Plant. 37: 283-287 (1976).

( 8 ) Jotterand-Dolivo, M. C. and P. E. Pilet: Wall hydroxyproline and growth of georeactive roots (Zea mays L.). Experientia 32: 874-875 (1976).

(9) Lake, J. V. and G. Slack: Dependence on light of geotropism in plant roots. Nature 191: 300$302(1961)$

(10) Masuda, Y.: Effect of light on growth inhibitor in wheat roots. Physiol. Plant. 15: 780-790 (1962).

(11) Mayor, G. and P. E. Pilet: Gradients racinaires: une nouvelle microméthode et son application a l'analyse des phosphomonoestérases acides. Physiol. Vég. 13: 479-487 (1975).

(12) Mayor, G. and P. E. Pilet: Longitudinal and transversal microgradient of acid phosphomonoestherase in growing and geostimulated maize roots. Physiol. Plant. 39: 236-238 (1977).

(13) Mohr, H. and J. Pichler: Der Einfluß hellroter und dunkelroter Strahlung auf die geotropische Reaktion der Keimlige von Sinapis alba L. Planta 55: 57-66 (1960).

(14) Pilet, P. E.: Auxines et inhibiteurs radiculaires endogènes. Physiol. Vég. 1: 171-190 (1963).

(15) Pilet, P. E.: Inhibiteurs de croissance racinaire et Énergie lumineuse. C. R. Acad. Sc. Paris 276: 2529-2531 (1973).

(16) Pilet, P. E.: Effect of light on the georeaction and growth inhibitor content of roots. Physiol. Plant. 33: 94-97 (1975).

(17) Pilet, P. E.: The light effect on the growth inhibitors produced by the root cap. Planta 130: 245-249 (1976).

(18) Pilet, P. E.: Effects of gravity on the growth inhibitors of geo-stimulated roots of Zea mays L. ibid. $131: 91-93$ (1976).

(19) Pilet, P. E.: Growth inhibitors in growing and geostimulated maize roots. In Plant Growth Regulation. Edited by P. E. Pilet. p. 115-128. Springer-Verlag, Berlin, Heidelberg, New York, 1977.

(20) Pilet, P. E.: The role of the cap in the geotropism of roots exposed to light. Z. Pflanzenphysiol. 89: $411-426$ (1978).

(21) Pilet, P.E.: Kinetics of light-induced georeactivity of maize roots. Planta (1979) (in press).

(22) Pilet, P. E. and D. Ney: Rapid, localized light effect on root growth in maize. Planta 144: 109-110 (1978). 
(23) Pilet, P. E., P. Steck and G. Mayor: ATP in growing roots: georeaction and light effect. Plant Sci. Let. 12: 343-347 (1978).

(24) Pradet, A.: Etude des adénosine-5'-mono, di et triphosphates dans les tissus végétaux I. Dosage enzymatique. Physiol. Vég. 5: 209-221 (1967).

(25) Pratt, L. and R. A. Coleman: Phytochrome distribution in etiolated grass seedlings as assayed by an indirect antibody-labelling method. Amer. J. Bot. 61: 195-202 (1974).

(26) Scott, T. K. and M. B. Wilkins: Auxin transport in roots IV. Effects of light on IAA movement and geotropic responsiveness in Zea roots. Planta 87: 249-258 (1969).

(27) Shaw, S. and M. B. Wilkins: The source and lateral transport of growth inhibitiors in geotropically stimulated roots of Zea mays and Pisum sativun. ibid. 109: 11-26 (1973).

(28) Sisler, E. C. and W. H. Klein: Effect of red and far-red irradiation on nucleotide phosphate and adenosine triphosphate levels in dark-grown bean and Avena seedlings. Physiol. Plant. 14 115-123 (1961).

(29) Steck, P. and P. E. Pilet: Croissance de segments de racine et contrôle énergétique. $C . R$. Acad. Sc. Paris 286: 1589-1591 (1978).

(30) Tepfer, D. A. and H. T. Bonnett: The role of phytochrome in the geotropic behavior of roots of Convolvulus arvensis. Planta 106: 311-324 (1972).

(31) Wagner, E., J. Tetzner, U. Haertlé and G. F. Deitzer: Endogenous rhythmicity and energy transduction VIII. Kinetics in enzyme activity, redox state and energy charge as related to photomorphogenesis in seedlings of Chenopodium rubrum L. Ber. Deutsch. Bot. Ges. 87: 291-302 (1974).

(32) Wain, R. L.: Root growth inhibitors. In Plant Growth Regulation. Edited by P. E. Pilet. p. 109-114. Springer-Verlag, Berlin, Heidelberg, New York, 1977.

(33) White, J. M. and C. S. Pike: Rapid phytochrome-mediated changes in adenosine 5'-triphosphate content of etiolated bean buds. Plant Physiol. 53: 76-79 (1974).

(34) Wilkins, H. and R. L. Wain: The root cap and control of root elongation in Zea mays L. seedlings exposed to white light. Planta 121:1-8 (1974).

(35) Wilkins, H. and R. L. Wain: The role of the cap in the response of the primary roots of Zea mays L. seedlings to white light and to gravity. ibid. 123: 217-222 (1975).

(36) Yunghans, H. and M. J. Jaffe: Rapid respiratory changes due to red light or acetylcholine during the early events of phytochrome-mediated photomorphogenesis. Plant Physiol. 49: 1-7 (1972). 
